The remaining time at the conference was allotted to contributions on theories of the origin of the primary radiation. This session began with introductory papers on the properties of the galaxy, the interstellar gas and the solar atmosphere. Prof. J. H. Oort described some recent work at Leyden confirming earlier results by Russian workers on the polarization of the light from the Crab nebula. The mean polarization over the central region of the nebula is 17 per cent; but there are indications that where a limited volume of the nebula can be isolated the polarization may be complete. Oort pointed out that it is possible to account for both the polarization at optical wavelengths and the observed intensity of radio noise if it is assumed that the emission is due to radiation from electrons of energy $\sim 10^{11} \mathrm{eV}$. spiralling in a magnetic field of $10^{-3}$ gauss. If this interpretation is correct, it opens up the interesting possibility that the Crab nebula may be a source of part of the cosmic radiation. The papers and discussion on the origin of the radiation left little room for doubt, however, that this problem still remains largely unsolved and is likely to feature as a subject for discussion at perhaps more than one cosmic-ray conference in the future.

The conference lasted for six days, and it will be appreciated that in a report of this length it has only been possible to mention a few of the many important contributions, selected in order to illustrate present trends in these fields.

\section{SECOND INTERNATIONAL SEAWEED SYMPOSIUM}

$\mathrm{F}$

OLLOWING the suggestion put forward at the first International Seaweed Symposium, held in Edinburgh in 1952 (see Nature, 170, 478; 1952), the Norwegian Institute of Seaweed Research (Norsk institutt for tang-og tareforskning) arranged the second such symposium in Trondheim during July 1416, when about $a$ hundred and twenty scientific workers and industria]ists from all over the world attended. In his opening address, Prof. Trygfe Braarud, chairman of the Board of Management of the Norwegian Institute of Seaweed Research, welcomed the delegates to Norway.

At the first session, dealing with "Algal Chemistry", Dr. E. I. Pereival (Scotland) opened the proceedings with a paper on the polysaccharide sulphuric acid ester of the green alga, Cladophora rupestris, hydrolysis of which revealed L-arabinose, D-galactose, $\mathrm{D}$-xylose, L-rhamnose and $\mathrm{D}$-glucose, this being the first reported occurrence of arabinose in a seaweed polysaccharide; attempts to elucidate the structure of this complex polysaccharide by standard pro. cedures were described. Dr. E. T. Dewar (Scotland) discussed the preparation, estimation and use of sodium laminarin sulphate as a heparin-substitute for preventing blood from clotting. The production of antibiotic substances by seaweeds was the subject of a paper by Prof. C. G. C. Chesters (England), in which certain littoral and sublittoral seaweeds have been examined for bacteriostatic activity; Polysiphonia fastigiata and Halidrys siliquosa are particularly good sources, and there is evidence of seasonal variation of antibiotic substances. The distribution of microbiological growth factors related to vitamin $B_{12}$, folic acid, folinic acid, niacin and pantothenic acid in the Rhodophyceae, Phaeophyceae, Chlorophyceae and Heterokontae was discussed by Prof. H. Lundin (Sweden) in a paper with L.-E. Ericson. The red and green algae generally contain higher amounts of vitamins than the brown algae, the maximum $\mathrm{B}_{12}$ content being possessed by Vaucheria dichotoma $(2 \cdot 8 \mu \mathrm{gm}$./gm. dry weight). The origin of vitamin $B_{12}$ factors is believed to be the bacteria living epiphytically on the plant, the algae merely concentrating and storing the vitamin but not synthesizing it. The carotene and carotenoid content of seaweeds was dealt with in two papers (by A. Haug and B. Larsen, and S. Liaaen and N. A. Sørensen). Mr. Haug (Norway) discussed the carotene content of Pelvetia canaliculata, Fucus vesiculosus, $F$. serratus and Rhodymenia palmata, the quantity in the fresh algae being generally much higher than in the dried materials and commercial seaweed meals; drying and storing conditions are important factors in carotene breakdown. Prof. Sørensen (Norway) dealt with the carotenoids of fresh $F$. vesiculosus and conditions leading to the formation of zeaxanthin; it is now believed that this pigment is formed from violaxanthin, and not fucoxanthin as originally suggested. Low-molecular carbohydrates were reviewed by Dr. B. Lindberg (Sweden), who has shown that the mono- and di- $\beta$-D-glucosides of mannitol are characteristic of many Phaeophyceae, while $P$. canaliculata also contains the corresponding glucosides of D-volemitol; brown algae possess 'laminitol', a $C$-methyl inositol. The glyceric acid-mannose glycoside of red algae is proved to be 2-D-glyceric acid $\alpha$-D-mannopyranoside, while two recently isolated glycosides are floridoside- $\alpha$-mannoside and 'isofloridoside' (1-glycerol- $\alpha$-D-galactopyranoside). The taxonomical value of these compounds was discussed.

Dr. F. T. Haxo (United States), in a paper with C. O hEochdha, reviewed the constituents of Porphyridium cruentum, a unicellular red alga which grows well but not prolifically in mineral-enriched seawater. The culture medium becomes viscous due to the presence of extra-cellular mucilage, which consists in part of a sulphated polysaccharide containing glucose, galactose, xylose and a uronic acid. Pigments include chlorophyll $a$, $\beta$-carotene, zeaxanthin and possibly lutein, while chromoproteins consist of a phycoerythrin and two phycocyanins. Three papers (by D. B. Smith, A. N. O'Neill and A. S. Perlin; S. T. Bayley; and W. Yaphe), read by Dr. E. Gordon Young (Canada), were devoted to the structure and degradation of carragheenin. By fractionation with potassium chloride, this polysaccharide has been separated into a potassium-sensitive fraction $(K$ carragheenin) and a potassium-insensitive fraction ( $\lambda$-carragheenin); the former contains $3: 6$-anhydro$D$-galactose and sulphated $D$-galactose residues in nearly equal proportions, while the latter appears to be mainly a sulphated $D$-galactose polymer. It is interesting to note that this anhydro-sugar in carragheenin is the enantiomorph of that present in agar. Useful information on the structure of the two fractions has been obtained by $\mathrm{X}$-ray and infra-red studies. Bacteria capable of hydrolysing carragheenin and agar have been isolated from sea-water and marine algae; the cell-free enzyme solutions are specific for the respective polysaccharides, and have been used to identify agar and carragheenin in red algal extracts. Examination of the breakdown products should yield fruitful results.

Dr. Young, in a paper with D. L. Vincent and D. A. I. Goring, described the comparison of sodium 
alginate samples from different species by examination of optical rotation, viscosity, ionic mobility and sedimentation-rate; viscosity is still the best criterion of degree of polymerization. Mr. A. Jensen (with I. Sunde, of Norway) gave details of the quantitative determination of alginic acid in seaweed samples by decarboxylating the mannuronic acid residues with 19 per cent hydrochloric acid and measuring the carbon dioxide potentiometrically. The method is convenient for routine analysis and is claimed to be more accurate than either the titrimetric or colorimetric procedure. The qualitative detection of small quantities of alginates in food, cosmetic and other products is often a matter of some difficulty, and consequently great interest was shown in a new method demonstrated by Mr. R. H. McDowell (England), in which the small quantity of alginate present is converted to calcium alginate, and the invisible precipitate is then rendered visible as characteristic blue floes by the addition of the dye, 'night blue'; by this means, as little as one part of alginate in a hundred thousand of solution can be detected. The detection of alginic acid in tissues by means of polarization optics was demonstrated in a series of slides by Dr. G. Andersen (Germany), whereby alginic acid, by virtue of its unique birefringent properties, is proved to occur in the middle lamellæ and primary cell-walls of the Phaeophyceae and is not accompanied by insoluble admixed 'hemicelluloses'.

The reaction of stearyl chloride on alginic acid was discussed by Mr. L. F. de Keyser (Belgium), the resulting ester being fractionated with ether to give the distearate and lower ester fractions. The seasonal variation in chemical composition of brown algae was the subject of papers by Mr. A. Haug (Norway) and Dr. C. Primo (Spain, read by Dr. J.-M. Perello), and the results were compared with those of previous workers. The decomposition of alginates and laminarin by micro-organisms occurring on decaying seaweed and in maritime muds was discussed by Prof. C. G. C. Chesters (England), the techniques used for assaying 'alginase' and 'laminarinase' activity being demonstrated. The results of chemical investigation of the decomposition products should yield valuable information on the structure of these two polysaccharides. The economies of the large-scale production of mannitol and laminarin from aqueous extracts of $L$. cloustoni frond were examined by $\mathrm{Mr}$. K. C. Reid (Scotland), who concluded that these two chemicals could be made available to industry at a reasonable price provided the weed residue was also processed for alginate. The drying of freshly harvested $L$. cloustoni was discussed by Dr. R. G. Gardner (Scotland, with T. J. Mitchell).

At the session devoted to the use of seaweed meals in human and animal nutrition, Dr. H. C. Wood (United States) read a paper (with G. L. Seifert) on Macrocystis pyrifera as a source of trace elements in human nutrition, and Mr. A. A. McInnes (Scotland) stressed the importance of seaweeds as a source of trace eloments for cattle, pigs, poultry and sheep. Sales of seaweed meal in the world to-day show that the claims of the seaweed producers are in fact real, although it may be difficult to prove these claims experimentally. The results of feeding Ascophyllum, Laminaria and Alaria meals to chicks and laying. hens were discussed by Prof. J. Høie (Norway); in general, the introduction of 3-8 per cent of seaweed meal into a basal ration which did not include any riboflavin-rich compounds led to increased growth and improved health in chicks and better-egg laying and hatching in pullets, although similar effects were obtained by the addition of yeast and grass meal. The iodine content of the eggs was considerably higher in seaweed-fed hens, and this was dealt with in greater detail in papers by I. Sunde (Norway, read by Mr. B. Larsen) and Prof. C. Romijn (Holland). The addition of $1 \mathrm{mgm}$. iodine as Ascophyllum meal per hen per day increased the iodine content of the egg about twenty times, while $20 \mathrm{mgm}$. per day as Laminaria hyperborea meal gave a 150 -fold increase. The iodine is concentrated in the water-soluble fraction of the yolk and not in the protein and lipoid fractions.

The botanical session was opened by Prof. Y. Yamada (Japan) with a paper on the distribution of Sargassum on the coast of Japan and its neighbouring regions, in which he said that the seventy known species of Sargassum can be divided into two typos from the distribution point of view, and most of these are utilized as fertilizer. Prof. A. A. Aleem (Egypt) described his underwater studies on the ecology of Macrocystis pyrifera on the coast of California by means of the Cousteau-Gagnan aqualung, by which maps and surveys of the kelp beds were made and correlated with surface observations by aerial photography; this would seem to be a very successful method of studying sublittoral ecology, and is by no means confined to seaweeds. Prof. W. E. Isaac (South Africa) reviewed the species occurring in the Saldanha-Langebaan Lagoon, off the south-west coast of South Africa, in which Gracilaria confervoides is cast up to the extent of about a thousand tons a year and forms the basis of a small agar industry. Miss B. T. Chiu (Hong Kong) discussed the seaweeds of economic importance in south China, where the abundant Sargassum species are harvested for uso as fertilizer and animal feedstuff, and many brown and red algae are used in human foods, medicine and the textile industry. Variations in the standing crop of Laminaria cloustoni have been observed for three areas off the coast of Scotland, and the significance of these survey results was dealt with by Mr. W. D. Richardson (with F. T. Walker, Scotland); in general, there was a decrease in seaweed growth between 1949 and 1953 , but 1954 showed a recovery in two out of the three areas.

Dr. A. D. de Virville (France) stressed the importance, both from a scientific and practical point of view, of having an accurate distribution map of marine plants of industrial value, and outlined a plan for the cartographical survey of the resources of the French coast; the Fucaceae, Iaminariaceae, Gigartinaceae and Zostereae are represented by different colours on the map, which then shows the location of these plants with a fair degree of accuracy. The paper by Miss C. MacFarlane (Canada) on studies in the seaweed populations of economic importance in Digby Neck area, Nova Scotia, was read by Dr. E. Conway (Scotland) and illustrated with many beautiful slides; seventy-five miles of the shore of the Neck and islands support sixty thousand tons of harvestable rockwesds, chiefly Ascophyllum nodosum, and Gigartina stellata and Laminaria beds are also extensive although tidal and topographical con. ditions make for difficult harvesting on most Fundy shores. Growth control in the Fucaceae and growth rings in stipes of Alaria esculenta were discussed by Dr. E. M. Burrows (England) and Dr. E. Baardseth (Norway), respectively, the latter also reading two papers (by H. Printz) dealing with the phenology 
and recolonization of Ascophyllum nodosum. During recent years reports have been received from various parts of the world that Ascophyllum is on the point of being exterminated due to its exploitation for seaweed meal, and this question of recuperation and recolonization aroused much interest among delegates; the best methods of harvesting this species were discussed in detail. Dr. H. Blackler (Scotland) discussed the time of reproduction and the rate of growth in certain Fucaceae, while Miss M. Naylor (England) dealt with the cytology of three British species of Laminaria, for which chromosome counts have been made both on the sporelings and the gametophytes. The resistance of Gracilaria confervoides to hydrogen sulphide was the subject of a paper by Mr. K. Stokke (Norway), who described experiments confirming the high resistance of the alga to this poison; the species was first recorded in Norway in 1935 and is frequently found in waters contaminated with hydrogen sulphide.

Many delegates contributed to the discussions following each paper, and it is hoped that the proceedings of the symposium will contain a résumé of these discussions together with the complete text of the papers presented. The meetings were held in the Norges Tekniske Høgskole, and three excursions were arranged in the Trondheimsf jord, when ample opportunity was given for studying the marine flora of the three localities. An excursion was also made to Molde and the west coast, and the delegates were able to view the coast at Hustad and to examine the littoral flora at Bud, where a delightful boat-trip was made to the archipelago of Bjørnsund.

It was unanimously agreed that similar symposia should be arranged in the future. Canada, France, Ireland and Spain were suggested as possible venues, and it was tentatively proposed to hold the third International Seaweed Symposium in Ireland in 1959 and the fourth in Spain in 1962. It was decided to appoint a standing committee to arrange the next Symposium.

E. T. Dewar

\section{SCIENTIFIC MANAGEMENT}

A NOTE in the programme of the National Conference on Science and Management arranged by the British Institute of Management and held at Harrogate during November 2-4 reads : "So fundamental are the changes with which the scientists are confronting us at the moment that many people are already talking in terms of a second industrial revolution. At the same time it is obvious that the face of Britain cannot be changed overnight. The responsibility for transferring new knowledge from the research laboratory to the production floor must rest with management. The British Institute of Management has therefore chosen as the theme of its National Conference for 1955 'The Impact of Science on Management in the Future'."

The conference embraced a wide range of subjectmatter. The 'impact' of the scientist was naturally most noticeable in the field of technology, and on the purely technical side managers had the opportunity of learning about such topical matters as the new materials and processes made practicable within the past few years and the uses and limitations of radioactive isotopes in industry. Discussion, however, was by no means limited to material and practical problems of production. The economics and the 'human implications' of technical innovation uach formed the subject of a separate panel debate, while a further panel discussed the function of the research association.

Papers presented by individual speakers indicated how scientific techniques could be applied to such operations as retailing and the analysis of market trends, while spokesmen for such specialities as accounting, sociology and economics each in their turn found time to wonder whether their own particular contribution could truly be described as 'scientific'. Looming behind each topic and linking together the whole conference was one important basic question: to what extent is the function of management itself based on scientific principles? For most of the managers attending, this question did not represent a new consideration. In the course of a very full programme they received added confirmation and demonstration of the means whereby the scientist can make a valuable contribution to the everyday task of management in industry, commerce and local government.

In a paper circulated to delegates but unfortunately, due to illness, not delivered in person, Prof. George C. Homans, of Harvard University, underlined the value of the general approach of the scientist. "The practical value of any science", he said, "is that by making experience subject to explicit intellectual control it speeds up the learning process and so sets intuition and judgment free to work on new ground rather than old. In something as important as management, anything that even begins to get us free of empiricism, or to set empiricism free for new advances, makes a contribution." Prof. Homans was referring in particular to the contribution of the sociologist. In a paper on "Operational Research", Sir Charles Goodeve, director of the British Iron and Steel Research Association, had some more general remarks to make about the application of the scientific method to management's task of planning for the future. "Getting rid of illusions about science and scientists", he said, "is one of the first essential steps in the whole field of the application of science, whether on the technical or the operational side of industry." Curves and diagrams of all types should be critically examined before acceptance by people other than those who produced them. "I have seen many examples", said Sir Charles, "of managers being overawed by curves. This is a more dangerous attitude than that of the opposite extreme. You should copy the approach of the scientists and disbelieve anything you are told until you can independently come to the same conclusions. A scientist always asks questions and will never believe the answers he is told. He will not accept an authoritative answer and is always demanding experimental proof of at least some reliable observations. The scientist believes that managers can make better decisions if they have the facts and an objective appreciation of the effects of the various sources of action open to them. It might pay the manager to wait for the scientist to do all this if he does not take too long over it."

That most unscientific word 'automation', receiving its due measure of attention within the theme of the conference, proved to be less alarming in its implications than might otherwise have been suspected. Under the treatment of Mr. John Diebold, who had travelled from the United States especially to speak at Harrogate, the subject appeared indeed to be concerned with the same fundamental and 